Original Research Paper

\title{
Evaluation of Gaussian Plume Model against CFD Simulations through the Estimation of CO and NO Concentrations in an Urban Area
}

\author{
${ }^{1,2}$ Mahmoud Bady \\ ${ }^{I}$ Department of Mechanical Engineering, Assiut University, Assiut 71516, Egypt \\ ${ }^{2}$ Department of Energy Resources Engineering, Egypt-Japan University of Science and Technology (E-JUST), \\ New Borg El-Arab City, Alexandria 21934, Egypt
}

Article history

Received: 06-12-2016

Revised: 18-04-2016

Accepted: 07-04-2017

Email: mahmoud.bady@ejust.edu.eg

\begin{abstract}
Dispersion of air pollutants, Carbon monoxide (CO) and Nitrogen oxide (NO), due to three point sources and a high-density traffic road in an urban area located near the center of Tokyo, Japan was studied using two different approaches. The first is an analytical approach using Gaussian Plume Model (GPM) while the second is a numerical approach using Computational Fluid Dynamics (CFD) simulations. In the first approach, the study area was divided into a fine grid and the traffic road was treated as a number of continuous adjacent stacks. The GPM was applied upon each stack and the concentration at each receptor was calculated using the principle of superposition. CFD simulations were carried out where steady state analysis was adopted and the standard k- $\varepsilon$ turbulence model was used. The concentrations calculated with the two approaches were compared together. The study results show that the agreement between the concentrations estimated by the two approaches was good in low-density built-up locations within the study area while significant deviation was obtained for high-density locations. Such result reflects the fact that the GPM is poor in predicting the actual concentrations in cases of densely urban areas.
\end{abstract}

Keywords: Gaussian Plume Model, Pollutant Concentration, Urban Area, Wind Flow

\section{Introduction}

During the last few decades, investigation of air pollutants transportation and dispersion in urban areas has become of major concern for the protection of air quality and also for compliance with air pollution regulations. The importance of pollutants transport investigation arises from the increased levels of pollutants in the atmospheric air of urban areas. Such increase has many reasons such as the continuing expansion of industries and the increased usage of motor vehicles coupled with population growth, especially in the major urban areas. These sources introduce a variety of air pollutants in large quantities into the atmosphere.

Although, the ambient air quality is regularly monitored to check pollutants levels by the regulatory agencies, regular monitoring of pollutants is not always feasible and it is cumbersome and costly. Thus, air pollution modeling has become an indispensable tool to assess the ambient air quality and to maintain pollutants level within permissible limits. Also, the ability to predict ground level concentrations of air pollutants is required to determine the environmental impact of existing sources to evaluate alternative new source locations, designs and controls and to estimate the effect of possible modifications to existing sources. Moreover, the impacts of new sources that do not yet exist can only be determined through modeling. Thus, air pollution modeling has become a primary tool in most air quality assessments.

Among many dispersion models, Gaussian Plume Model (GPM) is considered the most widely analytical approach for estimating the impact of air pollutants. It is computationally much more efficient, compared with other techniques regarding time and modeling efforts especially in large scale studies.

Another important approach for air quality modeling is the numerical technique using Computational Fluid 
Dynamics (CFD) simulations. CFD modeling is a general term used to describe the analysis of systems involving fluid flow, heat transfer and associated phenomena using computer-based numerical methods. With ever-increasing computer power, CFD techniques have been increasingly applied to the simulation of atmospheric problems (Xiaomin et al., 2005). Although it requires much extensive input data and consumes much time, the numerical technique using CFD simulations is a very useful tool in air quality assessment. Such simulations can describe the dispersion of air pollutants very well if they correctly set up to obtain reliable results.

Many researchers have studied the performance of Gaussian plume model in predicting pollutant concentrations in the urban area. Antonioni et al. (2012) carried out a comparison between different models describing the dispersion of neutral gas in an idealized urban-like environment. They used the experimental data available in the literature as a benchmark for assessing statistical performance for each model. Their results showed that; with the aid of several statistical measures, the performances of models such as GPM could be ranked differently on the basis of single parameters and so the choice of the correct parameter could be made keeping in mind the purpose of the application of the model. Leroy et al. (2010) compared the experimental results of krypton-85 dispersion, discharged from a 100 $\mathrm{m}$ high stack with calculations obtained from three Gaussian plume models: ADMS 4.0, Briggs and Doury. They concluded that; only the Briggs model correctly reproduced the measured values for the width of the plume, whereas the ADMS 4.0 model overestimated it and the Doury model underestimated it. However, no literature review was found concerning the evaluation of GPM results against CFD simulations results. Accordingly, the present study introduces a comparison between the performance of GPM approach versus numerical approach, through an analysis of air pollution problem in an urban area located near the center of Tokyo, Japan. The study focuses on the dispersion of carbon monoxide (CO) and nitrogen oxide (NO) since these two gasses are identified as the major pollutants which are being emitted from the sources mentioned above.

\section{Study Area}

The considered area of study, as shown in Fig. 1, is located near the center of Tokyo, Japan. It has many characteristics which gave the author an attention to study its air pollution problem. The primary source of pollution within that area is a high-density traffic road. It consists of two parts; the first part extends approximately to the north and has a length of $365 \mathrm{~m}$ and the second part makes an angle of $58^{\circ}$ with the south and its length is $333 \mathrm{~m}$. Also, there are three ventilation towers located along the traffic road for the underground tunnel under the road. These towers are treated in the analysis as three tall stacks. With respect to a selected origin, the coordinates of the three stacks are: $(0.8,41),(30,-52),(64,-106)$. Each of these stacks has a physical height of $45 \mathrm{~m}$ and an exit area of 50 $\mathrm{m}^{2}$. Transportation through the two sides of the traffic road and the emitted gasses from the three stacks play the major role in the problem of air pollution inside that region. For the purpose of the study, a domain of area $800 \times 800 \mathrm{~m}^{2}$ is considered to calculate the concentrations and distributions of $\mathrm{CO}$ and $\mathrm{NO}$ inside the study area using two different approaches.

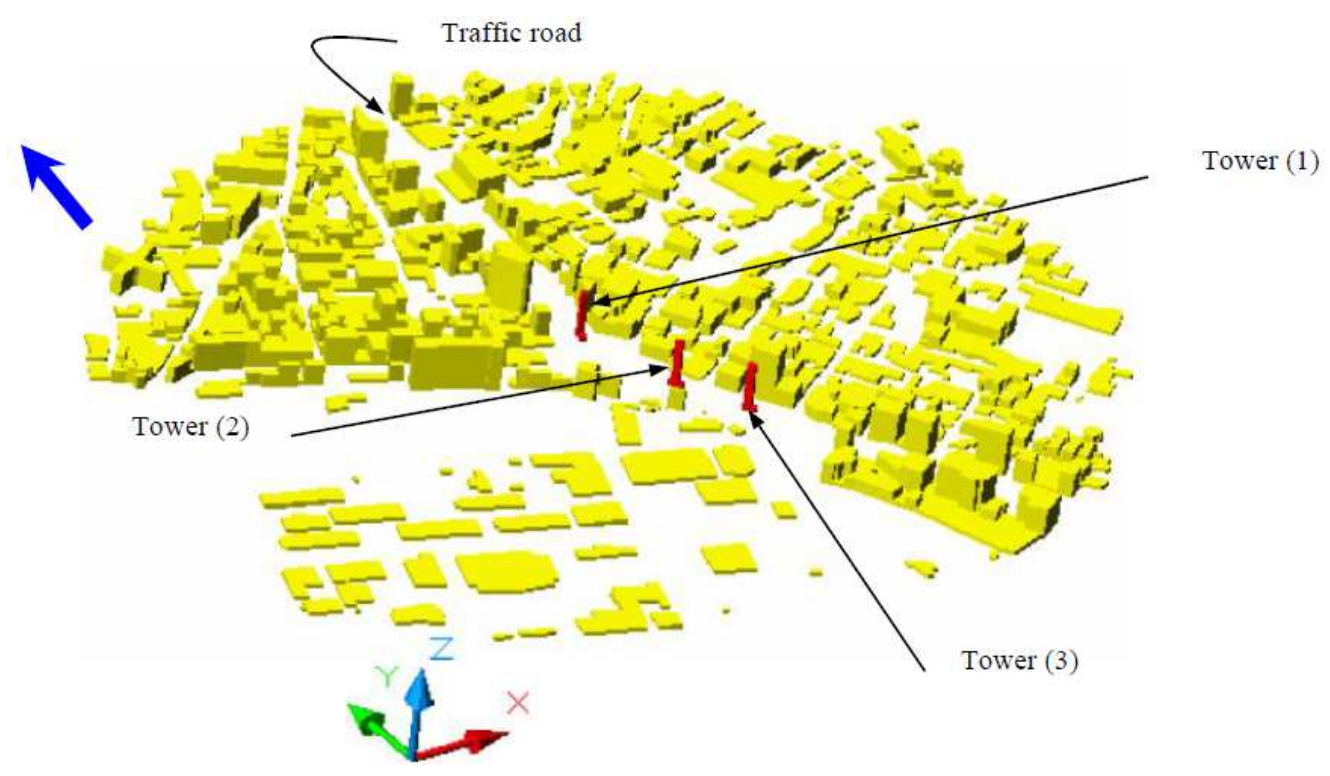

Fig. 1. Characteristics of the study area 


\section{Methodology}

\section{Gaussian Plume Model (GPM) Approach}

In order to apply GPM, the domain of study is simulated using a large number of grids. Each grid has a size of $5 \times 5 \mathrm{~m}$. The traffic road is divided into a current of continuous adjacent stacks. For each stack, the origin is transferred to the center of the considered stack and the modified $\mathrm{x}$-axis is set in the same direction of the wind, while the modified y-axis is taken perpendicular to the wind direction. For any receptor located within the area of study, the downwind and crosswind distances are computed relative to the new origin. Then, the GPM is applied for each point source.

\section{Point Sources (Ventilation Towers)}

The following equation gives the concentration of a gaseous pollutant emitted from a point source (El-Gamal et al., 2013; Enkeleida and John, 2010; Leroy et al., 2010):

$$
\begin{aligned}
& c=\frac{Q}{2 \pi u \sigma_{y} \sigma_{z}} * \exp \left(-\frac{y^{2}}{2 \sigma_{y}^{2}}\right) \\
& \left\{\exp \left(-\frac{(z-H)^{2}}{2 \sigma_{z}^{2}}\right)+\exp \left(-\frac{(z+H)^{2}}{2 \sigma_{z}^{1}}\right)\right\}
\end{aligned}
$$

Where:

$$
\begin{array}{lll}
c & = & \text { The pollutant concentration }\left(\mathrm{g} / \mathrm{m}^{3}\right) \\
Q & = & \text { The source strength }(\mathrm{g} / \mathrm{s}) \\
u & = & \text { The wind speed at stack tip level }(\mathrm{m} / \mathrm{s}) \\
y & = & \text { The crosswind distance }(\mathrm{m}) \\
z & = & \text { The vertical distance above ground }(\mathrm{m}) \\
\sigma_{y} \text { and } \sigma_{z}= & \text { The horizontal and vertical dispersion } \\
& & \text { parameters respectively }(\mathrm{m})
\end{array}
$$

$H$

$$
H=h_{s}+\Delta H
$$

Where:

$h=$ The physical stack height $(\mathrm{m})$

$\Delta h=$ The plume rise $(\mathrm{m})$

The plume rise can be calculated using Holland's formula (De Nevers, 2000; Islam and Roy, 2002):

$\Delta h=\frac{V_{s} D}{u}\left[1.5+0.00268 \times p \times D \times\left(1-\frac{T_{a}}{T_{s}}\right)\right]$

Where:

$V_{S}=$ The stack exit gas velocity $(\mathrm{m} / \mathrm{s})$

$D=$ The stack exit diameter $(\mathrm{m})$

$P=$ The atmospheric pressure (millibars)

$T_{s}=$ The stack exit gas temperature and

$T_{a}=$ The ambient air temperature $(\mathrm{K})$.

The characteristics of plume dispersion depend on the stability classification assigned to the scenario being studied. For dispersion estimation and modeling purposes, the levels of atmospheric stability are classified into six stability classes based on five surface wind speed categories, three types of daytime radiation and two types of nighttime cloudiness. These stability classes are referred to as Pasquill-Gifford stability classes and are depicted in Table 1 (Peavy et al., 1987). Horizontal and vertical dispersion parameters $\sigma_{\mathrm{y}}$ and $\sigma_{\mathrm{z}}$ are estimated using the Briggs formulae for urban sites (Griffiths, 1994), as given in Table 2 .

Table 1. Atmospheric stability classifications $\left(^{*}\right)$ (Peavy et al., 1987)

\begin{tabular}{llllll}
\hline & Day solar radiation & & Night cloudiness \\
speed $(* *)(\mathrm{m} / \mathrm{s})$ & - & Moderate & Slight & Cloudy $(\geq 4 / 8)$ & Clear $(\leq 3 / 8)$ \\
\hline$<2$ & Strong & A-B $(* * *)$ & B & E & F \\
$2-3$ & A & B & C & E & F \\
$3-5$ & A-B & B-C & C & D & D \\
$5-6$ & B & C-D & D & D & D \\
$>6$ & C & D & D & D & C
\end{tabular}

(*) A- Extremely unstable, B- Moderately unstable, C- Slightly unstable, D- Neutral, E-Slightly stable, F- Moderately stable; (**) Surface wind speed is measured at $10 \mathrm{~m}$ above the ground $(* * *)$ For A-B, B-C, or C-D conditions, average the values obtained for each

Table 2. Brigg's parameterization for urban sites(a) (Griffiths, 1994)

\begin{tabular}{lll}
\hline Class & $\sigma_{y}(\mathrm{~m})$ & $\sigma_{z}(\mathrm{~m})$ \\
\hline A-B & $0.32 \mathrm{x}(1+0.0004 \mathrm{x})^{-0.5}$ & $0.24 \mathrm{x}(1+0.001 \mathrm{x})^{-0.5}$ \\
C & $0.22 \mathrm{x}(1+0.0004 \mathrm{x})^{-0.5}$ & $0.20 \mathrm{x}$ \\
D & $0.16 \mathrm{x}(1+0.0004 \mathrm{x})^{-0.5}$ & $0.14 \mathrm{x}(1+0.0003 \mathrm{x})^{-0.5}$ \\
E-F & $0.11 \mathrm{x}(1+0.0004 \mathrm{x})^{-0.5}$ & $0.08 \mathrm{x}(1+0.0015 \mathrm{x})^{-0.5}$ \\
\hline
\end{tabular}

(a) Downwind distance $\mathrm{x}$ measured in meters 
The power law relationship is used to estimate the wind speed at stack level:

$u=u_{o}\left(z / z_{o}\right)^{n}$

Where:

$u_{o}=$ The reference wind velocity $(\mathrm{m} / \mathrm{s})$

$z_{0}=$ The reference height $(\mathrm{m})$

$n=$ An index

The value of the power-law exponent $n$ depends on the atmospheric stability category and the terrain type. The values of $\mathrm{n}$ for the six stability categories in urban areas are given in Table 3 (Peavy et al., 1987).

\section{Line Source (Traffic Road)}

For infinite continuous line sources, Equation 1 can be integrated to obtain an expression for the concentration at any point in the domain around the road (Ashoch and Patil, 1989; Venkatram and Horst 2006). The resulted equation has many restrictions related to wind direction and it needs a correction factor for the value of the used wind speed (Chock, 1977). For definite line sources, the problem is different. Usually, it is preferable to treat the traffic road as a line that contains a number of continuous point sources of the same characteristics of the road. Following that way, the line source here is divided into a current of continuous adjacent point sources as illustrated in Fig. 2. The number of point sources representing the traffic road was proportional to the road length and the diameter of each stack is assumed to be equal to the width of the road. The mechanism of diffusion from each point source is assumed to be independent of the presence of other point sources. The concentration at any receptor is estimated by applying the principle of superposition. The concentration at a receptor located at a certain point $P(x, y, z)$, is the sum of contributions from all the point sources making the line source (Bady et al., 2006).

Usually, wind speed value that used in concentration calculations is taken as the mean value at the same height of the source. In the case of ground level sources such as traffic roads, it 's hard to measure wind speed at such a small source height. Therefore, wind speed at a height of $10 \mathrm{~m}$ above ground level is considered. Such value is estimated using Equation 3.

\section{CFD Simulations Approach}

The most widely used approach for solving the NS equations is the time averaged, in which these equations are transformed into the Reynolds Averaged NavierStokes (RANS) set. For the simulation of CO and NO emissions, they were treated as two active scalars with fixed mass fluxes from both the traffic road and the three ventilation towers.

Since the area of study contains many geometric configurations such as residential houses and shopping centers, it was preferred to use a system of the unstructured grid because this type of meshes is very effective for conducting CFD simulations in complex urban areas (Huang et al., 2005). The unstructured grid system including 1,090,712 meshes for the study area was created as shown in Fig. 3.

The generalized logarithmic law was applied to the building walls and ground surface as smooth walls while the side and sky boundaries were treated as free slip surfaces. At inlet boundary, the constant flux layer assumption was adopted to generate a turbulent energy ' $\mathrm{k}$ ' and dissipation rate ' $\varepsilon$ '. The inflow wind speed was set to obey the one-fourth power law relationship and the inlet turbulence intensity was assumed to be $10 \%$ of the reference wind speed (Bady et al., 2008).

The Navier-Stokes equations were solved using the CFD code, STAR-CCM +, where the standard k- $\varepsilon$ model for turbulence was applied. The steady-state analysis was adopted and the second order upwind scheme (UD) was applied to the spatial difference since that scheme was specially adapted for unstructured meshes. The SIMPLE algorithm was applied for the calculations of velocity and pressure. The convergence criterion was chosen in such a way that; the residuals for all calculated variables decreased at each cell below a value of 10-6 for the calculations.

Table 3. Power-law exponents for the stability categories in urban areas (Peavy et al., 1987)

\begin{tabular}{lcccccc}
\hline Class & $\mathrm{A}$ & $\mathrm{B}$ & $\mathrm{C}$ & $\mathrm{D}$ & $\mathrm{E}$ & $\mathrm{F}$ \\
\hline$n$ & 0.15 & 0.15 & 0.20 & 0.25 & 0.30 & 0.30 \\
\hline
\end{tabular}

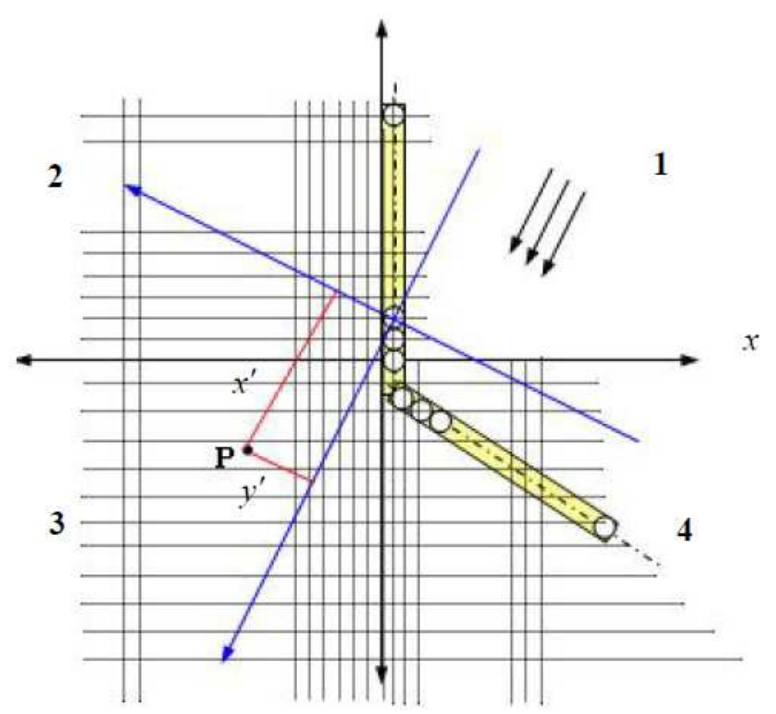

Fig. 2. Representation of the line source and the grid system 


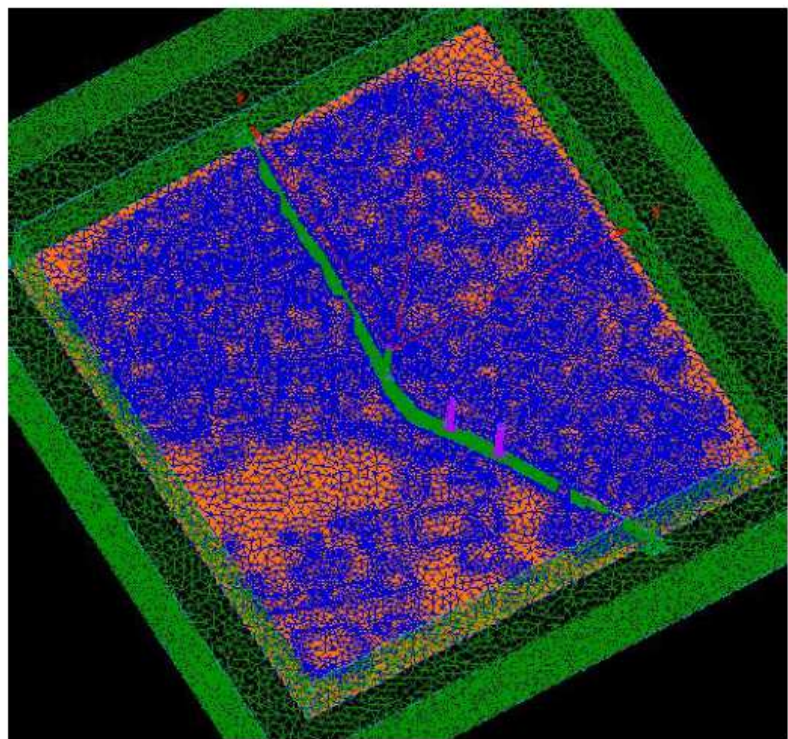

(a)

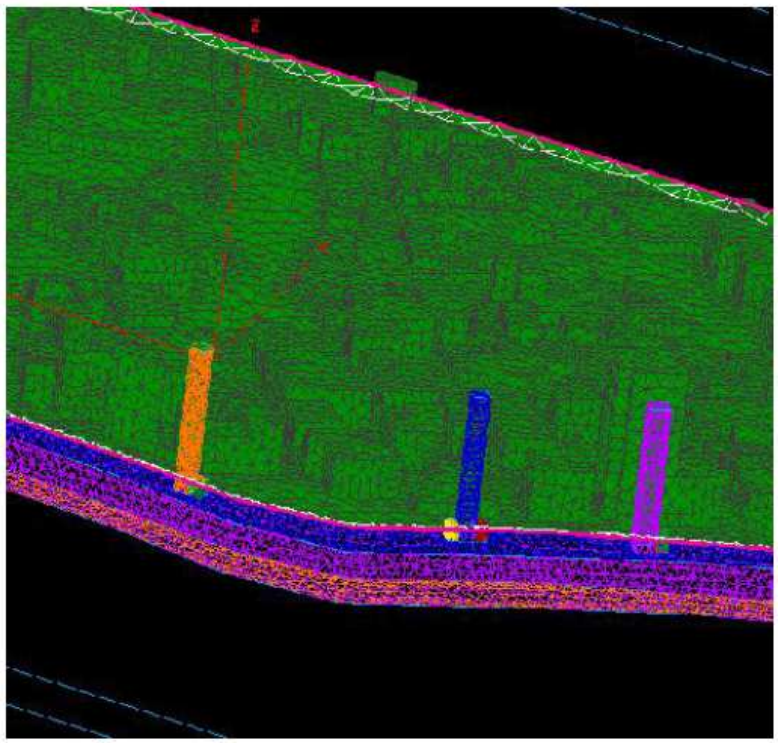

(b)

Fig. 3. Mesh system of the study area, (a) A plan view shows the whole study area, (b) A sectional side view shows the tunnel and the three ventilation towers

\section{Simulation Data}

Table 4 lists the data used in the calculations of $\mathrm{CO}$ and NO concentrations within the study area. Sources strength data and ventilation towers parameters were measured at the actual study area. The measured quantities were specifically designed to produce data suitable for CFD simulation and also for GPM calculations. The calculations of $\mathrm{CO}$ and $\mathrm{NO}$ concentrations were carried out using FORTRAN language for the GPM approach.

\section{Results and Discussion}

Figure 4 shows the wind flow field at $1.5 \mathrm{~m}$ height above ground, which is the pedestrian level. The average wind velocity in the open zone, where no building exists, is $1.8 \mathrm{~m} \mathrm{sec}^{-1}$. The velocity then decreases significantly to $0.3 \mathrm{~m} \mathrm{sec}^{-1}$ in the building colony due to the blocking effect of wind flow produced by buildings.

Figure 5 shows a sectional view of NO concentration distribution inside the underground tunnel, along the traffic road and through one of the ventilation towers. The maximum NO concentration inside the tunnel is 0.5 ppm and it decreases significantly during the plume way to the ventilation tower inlet. The average concentration along the ventilation tower is $0.26 \mathrm{ppm}$ and at the stack tip is 0.23 ppm.

Distribution characteristics of $\mathrm{CO}$ and $\mathrm{NO}$ concentrations are presented in Fig. 6 and 7, in which the concentration values obtained using CFD simulations are displayed in Fig. 6 and the concentration contour lines calculated using GPM are shown in Fig. 7.

These figures show high concentration values for $\mathrm{CO}$ and NO through the two parts of the traffic road. There are two important notes arise from the figure:

- The concentrations in the locations near the traffic road are significantly higher than those of the other sites in the study area. As the distance away from the road increases, the concentration decrease gradually which means that the pollutants are first emitted from the road and then transport away with the incident wind flow and disperse in the atmospheric air

- The average concentration of $\mathrm{NO}$ is greater than $\mathrm{CO}$ concentrations. This is attributed to the high emission intensity of NO compared with that of CO, as given in Table 4

\section{Comparison between the Results of the Two Approaches}

In order to compare the performance of the GPM approach against the CFD approach, the study area is divided into four quarters as illustrated in Fig. 2. Since most of the first quarter is located in the upwind region; no concentrations are detected in it. Accordingly, the comparison is conducted for the other three-quarters. Figure 8 presents a comparison between the concentrations of $\mathrm{CO}$ and $\mathrm{NO}$ calculated by the two approaches at some common points located inside the three-quarters. These points are extracted at a height of 1.5 $\mathrm{m}$ above ground, which is the pedestrian domain level. 


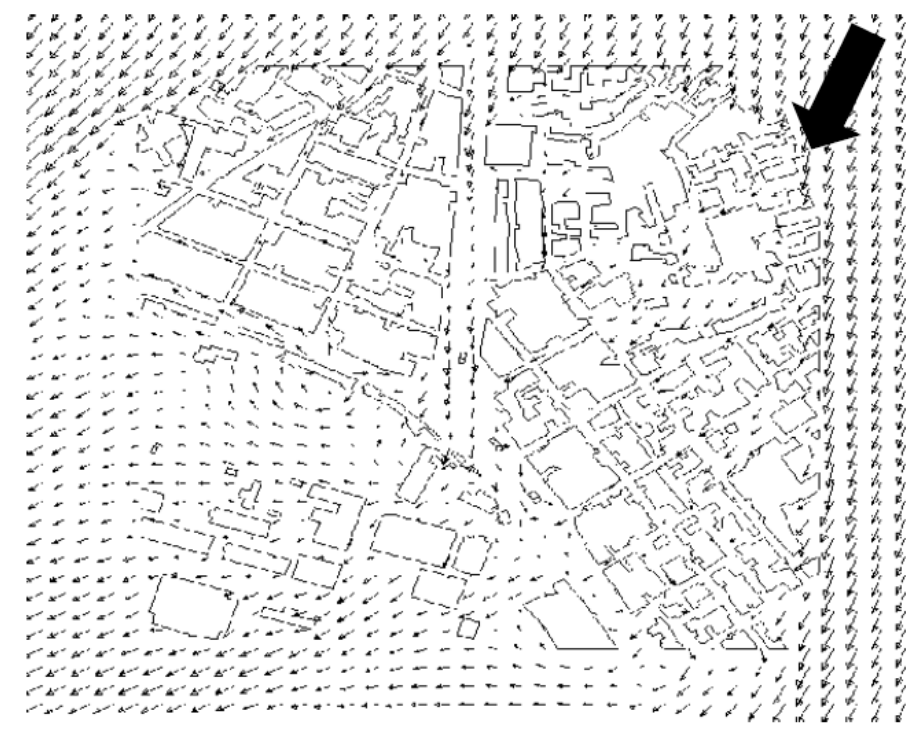

Fig. 4. Velocity vector distribution around the area of study

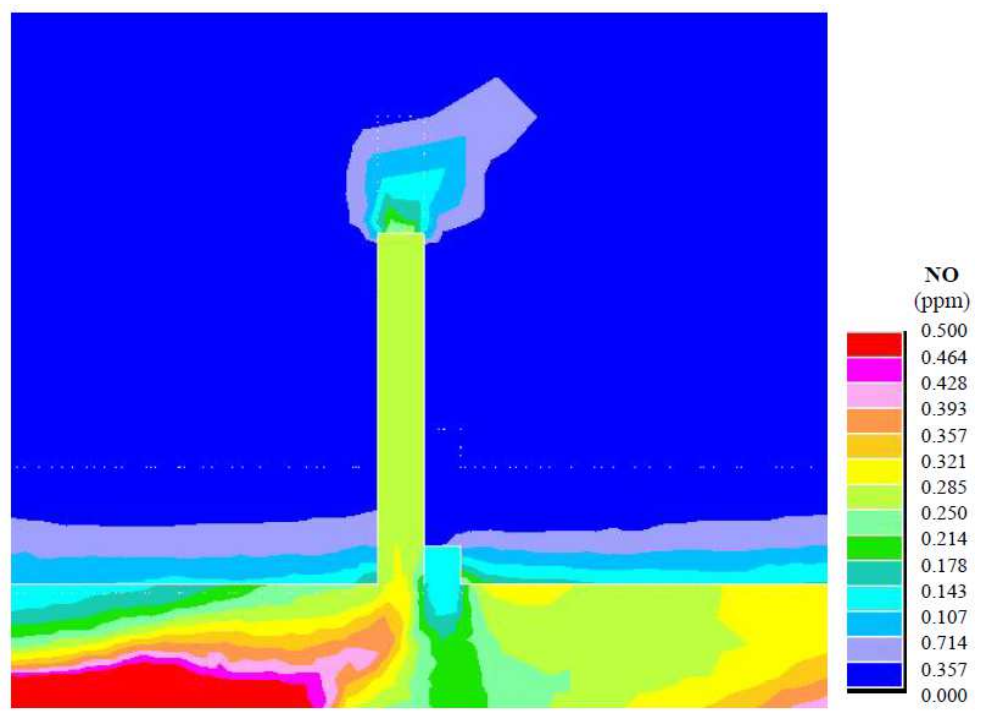

Fig. 5. A sectional view of the NO distribution along the traffic road and through one of the ventilation towers
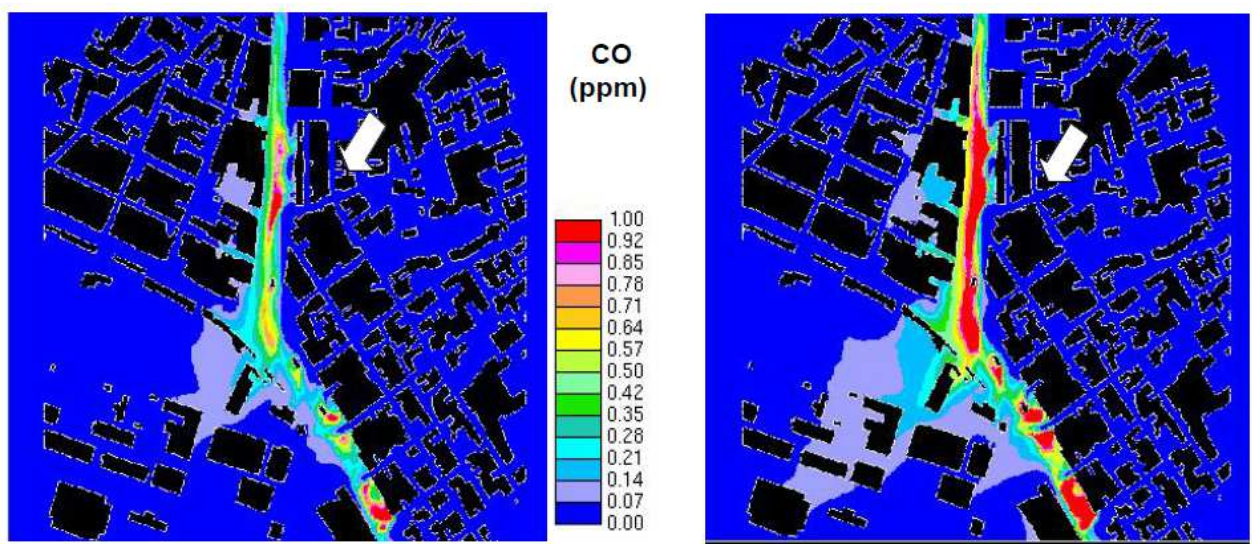

NO

(ppm)

Fig. 6. $\mathrm{CO}$ and $\mathrm{NO}$ concentrations inside the study area estimated using CFD simulations $(\mathrm{z}=1.5 \mathrm{~m})$ 

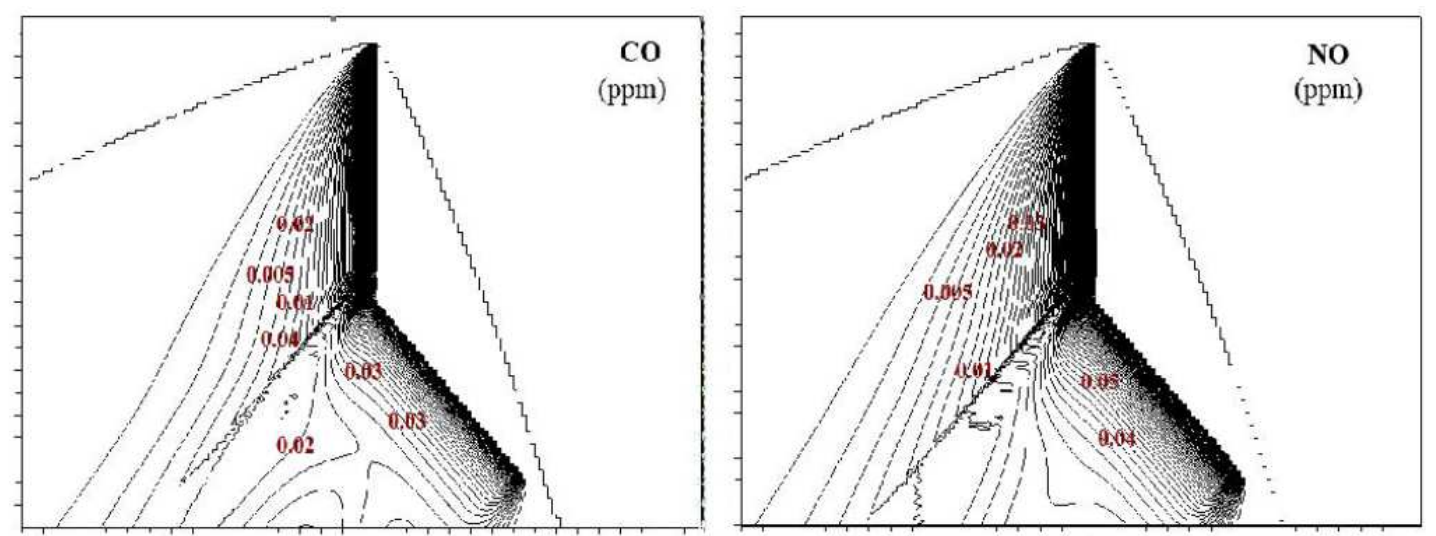

Fig. 7. $\mathrm{CO}$ and NO concentrations inside the study area estimated using GPM ( $\mathrm{z}=1.5 \mathrm{~m})$
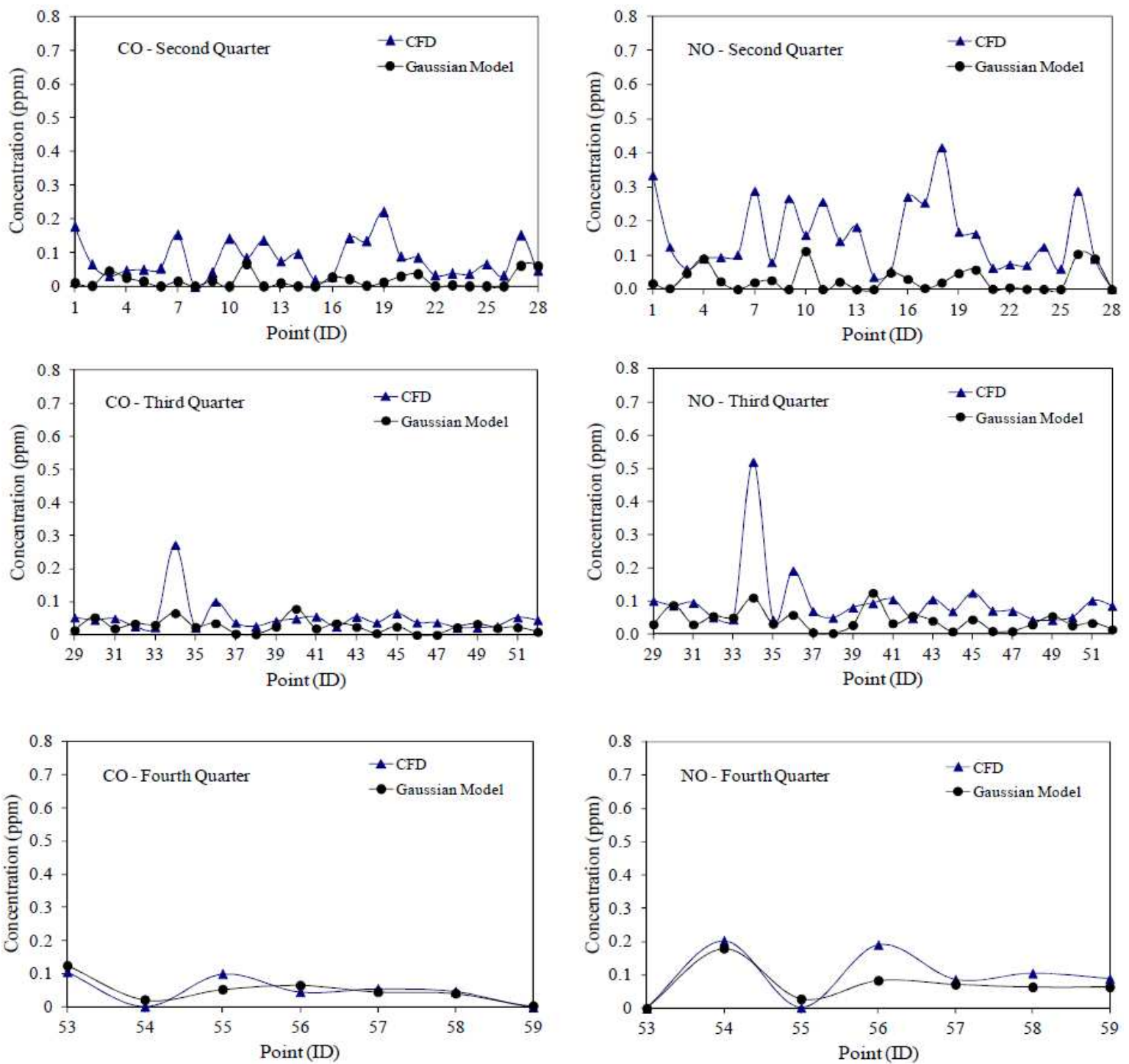

Fig. 8. Comparison between GPM and CFD results for $\mathrm{CO}$ and NO concentrations at different points located within the study area at $1.5 \mathrm{~m}$ height 
Table 4. Parameters and conditions of the calculations

Inlet

Outlet

Sides and sky

Wall and ground

Differential schemes

Pollution source strengths

Parameters of the three ventilation towers

Stability class

Table 5. The relation between CFD and GPM concentrations using logarithmic fitting model

\begin{tabular}{lllll}
\hline \multicolumn{1}{l}{ Table 5. The relation between CFD and GPM concentrations using logarithmic fitting model } & & \\
\hline Second Quarter & & $R^{2}$ & $a$ & $b$ \\
& {$[\mathrm{CO}]$} & 0.043 & 0.0217 & 0.0019 \\
Third Quarter & {$[\mathrm{NO}]$} & 0.026 & 0.0382 & 0.0049 \\
& {$[\mathrm{CO}]$} & 0.144 & 0.0679 & 0.0133 \\
Fourth Quarter & {$[\mathrm{NO}]$} & 0.199 & 0.1042 & 0.0249 \\
& {$[\mathrm{CO}]$} & 0.379 & 0.1031 & 0.0132 \\
& {$[\mathrm{NO}]$} & 0.463 & 0.1040 & 0.0073 \\
\hline
\end{tabular}

In order to carry out the comparison, it was found that the number of common points in the two approaches is 59 points; 28 points in the second quarter, 24 points in the third quarter and 7 points in the fourth quarter.

As shown in Fig. 8, a significant difference is observed between the concentrations estimated by the two approaches in the high building density locations, such as the case of the second quarter. The absolute difference between the concentrations estimated by the two approaches is more than $100 \%$ at almost all points in that quarter. In fact, the large difference reflects the disadvantage of GPM in predicting the concentrations in cases of densely built-up areas. It doesn't take the buildings (obstacles) effect into consideration. Since buildings influence both the wind speed value and wind direction, the diffusion of air pollutants is affected. Another important point is that; the GPM assumes constant wind direction between the source and the receptor and it doesn't account for the direction variation that can happen due to the presence of obstacles. That reason can explain the lower concentration values estimated by GPM compared with those obtained by CFD simulations.

In the third quarter where the building density is medium, the agreement between the results of the two approaches is acceptable as the deviation lies under an average value of $55 \%$ for $\mathrm{CO}$ and $59 \%$ for $\mathrm{NO}$. $\mathrm{u}=\mathrm{u}_{\mathrm{o}}\left(\mathrm{z} / \mathrm{z}_{\mathrm{o}}\right)^{0.25}, \mathrm{u}_{\mathrm{o}}=1 \mathrm{~m} \mathrm{sec}^{-1}, \mathrm{z}_{\mathrm{o}}=74.6 \mathrm{~m}$

$\mathrm{k}=1.5\left(\mathrm{u}_{\mathrm{o}} \times \mathrm{I}\right)^{2}, \mathrm{I}=10 \%$ (Bady et al., 2008; Huang et al., 2008)

$\varepsilon=C_{\mu}^{0.5} \times k \times \frac{\partial u}{\partial z}, C_{\mu}=0.09$

Inlet wind direction: NNE, $67.5^{\circ}$ with the horizontal axis

Zero normal derivatives

Free slip condition

Generalized logarithmic law $(\mathrm{E}=9)$

Convection term: Second order upwind scheme (UD)

Diffusion term: CD scheme

Concentration: First order UD scheme

Road: $\mathrm{NO}=1.290 \mathrm{~g} / \mathrm{s}, \mathrm{CO}=0.710 \mathrm{~g} / \mathrm{s}$

Tower $1: \mathrm{NO}=0.488 \mathrm{~g} / \mathrm{s}, \mathrm{CO}=0.453 \mathrm{~g} / \mathrm{s}$

Tower $2: \mathrm{NO}=0.385 \mathrm{~g} / \mathrm{s}, \mathrm{CO}=0.359 \mathrm{~g} / \mathrm{s}$

Tower 3: $\mathrm{NO}=0.925 \mathrm{~g} / \mathrm{s}, \mathrm{CO}=0.860 \mathrm{~g} / \mathrm{s}$

Stack-tip exit velocity $=6.3 \mathrm{~m} / \mathrm{s}$

Physical height $=45 \mathrm{~m}$

Exit area $=50 \mathrm{~m}^{2}$ (square stacks)

Exit temperature $=\mathrm{T}_{\text {atm }}$ (assumption)

Neutral
Finally, in the fourth quarter, where no buildings exist or where the building density is very small, a good agreement between the results of the two approaches is obtained. Such result shows the advantage of using GPM over the numerical modeling-regarding modeling time and effort- in predicting the concentrations of air pollutants in cases of open areas where no obstacles exist, or where the number of buildings is limited in such a way that; it makes no resistance to wind flow.

Besides the disadvantage of the GPM in predicting the actual concentration values in case of high densely built-up areas, the difference between the calculated concentrations of the two approaches can be attributed to the following:

- Both the intersection region between the two parts of the road and the edge effects caused by the end of the line source was not accounted for in the analysis. These may affect the concentration calculations since the edge effects become more important in the sense that they extend to greater crosswind distances as the distance downwind from the source to the receptor increases

- As mentioned before, it's hard to measure the wind speed at the same level of the traffic road. That difficulty drives us to estimate another value; 
usually taken at a height of $10 \mathrm{~m}$. Since the value of $\mathrm{u} 10$ is greater than the value of $\mathrm{u} 0$, the pollutant concentration calculated by the GPM is lower than the value calculated using CFD approach

- The two assumptions of neutral atmospheric conditions and the ventilation tower exit temperatures to be equal to the ambient temperature, decrease the value of the plume-rise term. That effect increases the concentration in the near area around the road and decreases it as the distance from the road increases

- Dividing the line source to a current of ground level point sources and using the assumption which states that the mechanism of diffusion from each point source is independent of the presence of other point sources, may become questionable if the line source has a self-generated turbulence such as the present case. The effect of such assumption appears clearly in the large deviation between the results of the two approaches in the second quarter only because the emissions from the traffic road have negligible effect on the calculated concentrations inside the other two-quarters

\section{Evaluation of GPM}

In order to provide a quantitative relation between the concentration values obtained by CFD simulation and those achieved by GPM, a scatter diagram is constructed. Then, the best fitting mathematical relationship is investigated and the best results are obtained with the logarithmic fitting model:

$C_{C F D}=a+b \times \log \left(C_{G P M}\right)$

Table 5 presents the results of the analysis in the three-quarters of the study area for both $\mathrm{CO}$ and $\mathrm{NO}$ concentrations.

From these results, it appears that; for the second quarter, only $4.3 \%$ of the variance $\left(\mathrm{R}^{2}=0.043\right)$ of $\mathrm{CO}$ and $2.6 \%$ of the variance $\left(\mathrm{R}^{2}=0.026\right)$ of $\mathrm{NO}$ concentration values estimated by CFD simulations can be explained by GPM concentrations.

For the third quarter, only $14.4 \%$ of the variance $\left(\mathrm{R}^{2}=0.144\right)$ of $\mathrm{CO}$ and $19.9 \%$ of the variance $\left(\mathrm{R}^{2}=\right.$ 0.199 ) of NO concentration values estimated by CFD simulations can be explained by GPM concentrations. On the contrary, for the fourth quarter, $37.9 \%\left(\mathrm{R}^{2}=\right.$ $0.379)$ and $46.3 \%\left(\mathrm{R}^{2}=0.463\right)$, respectively, of the variance of $\mathrm{CO}$ and $\mathrm{NO}$ concentrations values can be associated with the variations of the GPM concentrations.

These results confirm the fact that; in the areas where no buildings exist or where the building density is very small, GPM is a useful and quick tool to evaluate the air quality conditions and to predict the concentration distribution within the study area. On the other hand, since the GPM assumes constant wind direction and wind speed and it doesn't account for the variations that may occur due to the presence of obstacles, the concentration values estimated by GPM become far from those estimated by CFD simulations. Although numerical simulation results have some accuracy limitations due to the assumptions associated with the applied turbulence model, convergence criterion and grid-dependence solution, it is still a valuable tool for the computations of airflow and pollutant transport in urban environments.

\section{Conclusion}

The objective of the present study was to evaluate the performance of Gaussian Plume Model approach in comparison with a numerical approach using CFD simulations, through a study of air pollution problem in an urban area located near the center of Tokyo, Japan.

The study results show that; the Gaussian plume model is computationally much more efficient, compared with the CFD simulations regarding time cost and modeling effort, especially in large-scale studies, but unfortunately, it is poor in predicting the actual concentrations values in cases of high densely built-up areas. With respect to elevated sources, GPM can be used to estimate pollutant concentrations, where obstacles such as buildings have little influence on the diffusion characteristics of pollutants and velocity flow field at such levels. In the case of low-level sources, it is not easy to estimate the pollutant concentrations using GPM due to the effect of surrounding obstacles which make pollutant removal efficiency by the wind vary from one location to another within the same domain. In practice, in order to predict the concentration of pollutants in an urban space, wind tunnel experiments and CFD simulations are used to estimate pollutant concentrations for this type of source. The CFD simulations are able to describe such phenomena very well, but they need to be correctly set up, tested and validated to obtain reliable results.

\section{Acknowledgment}

The author acknowledges the support from EgyptJapan University of Science and Technology (E-JUST), Alexandria, Egypt.

\section{Ethics}

This article is original and contains unpublished material. The corresponding author confirms that all of the other authors have read and approved the manuscript and no ethical issues involved. 


\section{References}

Antonioni, G., S. Burkhart, J. Burman, A. Dejoan and A. Fuscob et al., 2012. Comparison of CFD and operational dispersion models in an urban-like environment. Atmospheric Environ., 47: 365-372. DOI: 10.1016/j.atmosenv.2011.10.053

Ashoch, K. and S. Patil, 1989. A general finite line source model for vehicular pollution prediction. Atmos. Environ., 23: 555-562. DOI: 10.1016/0004-6981(89)90004-8

Bady, M., S. Kato, Y. Ishida and H. Huang, 2008. Towards the application of indoor ventilation efficiency indices to evaluate the air quality of urban areas. Build. Environ., 43: 1991-2004. DOI: 10.1016/j.buildenv.2007.11.013

Bady, M., S. Kato, R. Ooka, H. Huang and T. Jiang, 2006. Comparative study of concentrations and distributions of $\mathrm{CO}$ and $\mathrm{NO}$ in an urban area: Gaussian Plume Model and CFD Analysis. Proceedings of the 14th International Conference on Modelling, Monitoring and Management of Air Pollution, (MAP' 06), Southampton, England.

Chock, P., 1977. A simple line-source model for dispersion near roadways. Atmos. Environ., 12: 823-829. DOI: 10.1016/0004-6981(78)90019-7

El-Gamal, H., M. El-Azab, A. Abdel Mageed, M. Bady and M. Hasabelnaby et al. 2013. Monstrous hazards produced by high radioactivity levels around Assiut thermal power plant. Am. J. Environ. Sci., 9: 388-397. DOI: 10.3844/ajessp.2013.388.397

Enkeleida, L. and M.S. John, 2010. An inverse Gaussian plume approach for estimating atmospheric pollutant emissions from multiple point sources. Atmos. Environ., 44: 1097-1107. DOI: 10.1016/j.atmosenv.2009.11.039

Griffiths, F., 1994. Errors in the use of the Briggs parameterization for atmospheric dispersion coefficients. Atmos. Environ., 28: 2861-2865. DOI: $10.1016 / 1352-2310(94) 90086-8$
Huang, H., R. Ooka and S. Kato, 2005. Urban thermal environment measurements and numerical simulation for an actual complex urban area covering a large district heating and cooling system in summer. Atmos. Environ., 39: 6261-6480. DOI: 10.1016/j.atmosenv.2005.07.018

Huang, H., R. Ooka, H. Chen and S. Kato, 2008. CFD analysis on traffic-induced air pollutant dispersion under a non-isothermal condition in a complex urban area in winter. J. Wind Eng. Indust. Aerodynam., 96: 1774-1788. DOI: 10.1016/j.jweia.2008.02.010

Islam, M. and G.D. Roy, 2002. A mathematical model in locating an unknown emission source. Water Soil Poll., 136: 331-345. DOI: $10.1023 / \mathrm{A}: 1015210916388$

Leroy, C., D. Maro, D. Hébert, L. Solier and M. Rozet et al., 2010. A study of the atmospheric dispersion of a high release of krypton- 85 above a complex coastal terrain, comparison with the predictions of Gaussian models (Briggs, Doury, ADMS4). J. Environ. Radioactivity, 101: 937-944. DOI: 10.1016/j.jenvrad.2010.06.011

De Nevers, N., 2000. Air Pollution Control Engineering. 2nd Edn., McGraw-Hill Publishing, Boston, ISBN-10: 0070393672, pp: 586.

Peavy, H., D. Rowe and T. George, 1987. Environmental Engineering. 7th Edn., McGraw-Hill Publishing.

Venkatram, A. and T. Horst, 2006. Approximating dispersion from a finite line source. Atmos. Environ., 40: 2401-2408.

DOI: $10.1016 /$ j.atmosenv.2005.12.014

Xiaomin, X., H. Zhen and S. Jia, 2005. Impact of building configuration on air quality in street canyon. Atmos. Environ., 39: 4519-4530. DOI: $10.1016 /$ j.atmosenv.2005.03.043 